\title{
Castor Oil and Its Derivatives' With Market Growth, Commercial Perspective: Review
}

\author{
Omprakash H Nautiyal* \\ Professor and consulting scientist, India
}

Submission: April 25, 2018; Published: May 11, 2018

"Corresponding author: Omprakash H Nautiyal, Professor and consulting scientist, 102, Shubh Building, Shivalik II, TP13, Canal Road, Chhani Jakat Naka, Vadodara 390024, Gujarat, India, Email: opnautiyalus@yahoo.com

\begin{abstract}
Within the chemical industry oleo-chemicals from Castor beans carry a strong and potential pattern. With some of the old important processes and products are replaced by the new in its constant changes. Some products over the years in contrast that were decline have been revived in accordance with the introduction of new technology and applications. New market demands have mounted heavy pressure on castor chemistry and have responded with great vigor. BSS castor oil is used in wide variety of applications and is the starting material for many other derivatives of castor oil. In pharmaceuticals and cosmetics it is used as an ingredient in formulations. It combines well with styrene and diisocyanates for film forming as well varnish. It is substantially insoluble infusible polymer and is used as lubricant component of coatings for vitamin and mineral tablets. It is also important ingredient for petroleum oil and de emulsification. Ricinoleic acid is also known as castor oil acid and belongs to a family of the unsaturated fatty acid. The Principal Castor Reactions are as follows; pyrolysis, polyamide11, hydrogenation, dehydration, caustic fusion, sebacic acid, undecylenic acid, heptaldehyde, sulfation/sulfonation, alkoxylation, oxidation/polymerization, esterification, dimerization, quaternaries, and engineering resin (interpenetrating networks).
\end{abstract}

Keywords: Castor Oil; 12-hydroxy Stearic acid; Ricinoleic Acid; Reactions; HCO; DCO

\section{Introduction}

Oleo-chemicals from Castor experience a meaningful pattern within the chemical industry. Its constant changes, with some of the old important processes and products are replaced by the new. Some products over the years in contrast that were decline have been revived in accordance with the Introduction of new technology and applications. New market demands have mounted heavy pressure on castor chemistry and have responded with great vigor. Among all the vegetable oils Castor oil is a most unusual product being more versatile. The concentration of most oils is either one or two applications, such as for edible purposes (cotton seeds, soya, corn, peanut, rapeseed, canola, sunflower, coconut and palm). According to economic factors many of these are interchangeable. Some of these find other uses, such as in coatings, inks lubricants, detergents and soaps. With a wide diversity of commercial applications castor has considerably more uses directly related to the unique hydroxyl fatty acid structure [1].

BSS castor oil is used in wide variety of applications and is the starting material for many other derivatives of castor oil. In pharmaceuticals and cosmetics it is used as an ingredient in formulations. It combines well with styrene and diisocyanates for film forming varnish. It is substantially insoluble infusible polymer and is used as lubricant component of coatings for vitamin and mineral tablets. It is also important ingredient for petroleum oil and de emulsification. It also impregnates capacitor as a sonar transducer fluid and as a dielectric material for electrical condensers. Polyurethane casting resins, fluid for automobiles, trucks and machinery are the other applications of castor oil. It also serves as starting material for other derivatives of castor oil.

12-hydroxy Stearic acid is the mixed fatty acid recovered by hydrolysis of hydrogenated castor oil with high melting point. It is brittle, waxy solid at ambient temperatures. Its deterioration must be protected by storing away from heat. It is insoluble in water and has very negligible solubility in many organic solvents. 12-HSA is non toxic and non hazardous. 12-HSA is utilized in the manufacture of lithium and calcium greases and acrylic polymers. In molding of plastics it finds application as an internal lubricant. It also has applications in aqueous and non aqueous coatings for automotive, equipment, appliances and architecture. Wool is treated with it for its shrink resistance. It is also used as coating liners for the interior of metal food and beverage containers. Aviator and synthetic rubber finds its application as an internal lubricant as well as theology modifier in inks. Specialty chemicals esters as ethoxylates and sulfates also find the use of it beside from plasticizers, textiles, cosmetics and metal working operations [1].

\section{Ricinoleic Acid}

Ricinoleic acid is also known as castor oil acid and belongs to a family of the unsaturated fatty acid. It is a viscous yellow 
liquid having melting point $5.5 \mathrm{oC}$ and boiling point $245 \mathrm{oC}$. It is immiscible with water and miscible with most of the organic solvents. Hydrolysis of castor oil yields it. It has uses in textiles finishing, in coating inks and in making soaps. Ricinoleic acid can be reacted with bases like caustic, ammonia, ethanolamines, to prepare soaps. These materials find its applications in cutting oils, industrial lubricants, emulsifiers and metal working compounds and impart lubricity, and rust proof characteristics. Ricinoleic acid is helping aid in making transparent bar soaps and high solids liquid soaps. It also enables the homogenization of phenolic and cresylic ingredients in industrial germicides, disinfectants, and heavy duty detergents. It is also an efficient pigments and dye dispersants that finds uses in inks, coatings, plastics, cosmetics and so on. Its sodium and potassium soaps are emulsifiers and foam stabilizers. It finds very important use in manufacturing poly glycerol poly ricinoleate (PGPR) a key ingredient in chocolates products. The sodium soap is useful as emulsifier, stabilizer, and de foam for emulsion polymerization of resins such as PVC and PVAC. It is also used for the treatment of leather. It provides good wetting, flexibility and softening properties to leather [2].

\section{Properties of Pigments and Dispersing Dyes}

Castor oil and many of its derivatives such as esters, hydrogenates and ethoxylates are well understood for their ability to wet surfaces acting as excellent carriers of pigments and dyes. Typical as colors for food stuffs, plastics, lipstick, paints, lacquers, coatings, inks, sealants, adhesives and color concentrates for plastics.

\section{Reactions}

As per current commercial practice many castor reactions are utilized as described follow. However there are certain limiting factors that must be recognized. An important illustration is the formation of estolides resulting from a linkage between hydroxyl and carboxyl groups. On storage the hydroxyl in ricinoleic acid forms an ester with the carboxyl. Decline of both hydroxyl value and acid value goes down as reaction proceeds. The change is well known with commercial ricinoleic acid and the two values can change by $5 \%-10 \%$ within 90 days from original production. The subject of castor estolides is reviewed by Modak and Kane which has an important list of references. There are citations where theoretically sound reaction mechanisms cannot be undertaken because of this interference. The ricinoleic acid structure explains why it could not be refined or purified by distillation by the conventional commercial procedure for purifying other fatty acids. Distillation affects the hydroxyl-acid linkage produces an alteration as the product is no longer ricinoleic acid. Factually, the estolide formation becomes one stage in the conversion to dehydrated castor fatty acids, the process for which is explained in this section [2].

In accordance of actual castor tonnage consumption the reactions are presented in order. The comparison of hydrogenated castor with polyamide 11 is difficult to compare. The latter is the larger, producing finished product by one manufacturer. Numerous hydrogenaters, found worldwide. Their product finds applications as an intermediate for several different end products. Polyamide is arbitrarily placed first and the volume of the two is comparable. The Principal Castor Reactions are as follows; Pyrolysis, Polyamide 11, Hydrogenation, Dehydration, Caustic Fusion, Sebacic Acid, Undecylenic Acid, Heptaldehyde, Sulfation/Sulfonation, Alkoxylation, Oxidation/Polymerization, Esterification, Dimerization, Quaternaries and Engineering Resins (Interpenetrating Networks) [2].

\section{Castor Oil and Derivatives in Liquid Carbon Dioxide}

Castor oil, Heptaldehyde and heptyl alcohol were included in a study of the mutual solubility of liquid carbon dioxide with each of 261 other substances. The solubility of carbon dioxide in each substance determined as such as was the solubility of each substance in carbon dioxide. 464 ternary systems were prepared with triangular graphs. Advanced research in physical properties of organic chemicals this project was to establish fundamental properties [3].

\section{Process Description for Castor Oil and Its Derivatives}

\section{Process Description for Hydrogenated Castor Oil [HCO]:}

a) The raw material, bleached castor oil (BSS grade) is processed under vacuum condition at a temperature of around $160 \mathrm{oC}$ in presence of nickel catalyst.

b) No sooner does the raw material reaches its required temperature, the vacuum is stopped and hydrogen is fed, while the stirrer is still operating.

c) The hydrogen feed is closed as the required degree of hydrogenation is achieved and after this, hydrogenated product is started cooling.

d) As the product temperate reaches around $100^{\circ} \mathrm{C}$, the final product gets filtered, cooled and then conveyed to flaking unit for flaking and bagged.

Process Description for Dehydrated Castor Oil (DCO): The reaction vessel is fed with castor oil stock grade through deaerator vessel. The oil gets dried in this vessel and completely freed from air, a higher temperature and vacuum is maintained in the reaction vessel which, continuously re-circulate the oil in the presence of a catalyst. The castor oil dehydrated which increases the un-saturation level and brings down the hydroxyl content of castor oil. The uniform quality of the product by all this process is maintained. The oil is finally passed through heat exchangers for cooling and then catalyst filtration as soon as the required degree of un-saturation and dehydration is met. After the filtration, the product is charged to a decolorizing vessel for removing the excess color from the oil [3].

Process Description for 12-Hydroxy Stearic Acid (12HSA): The hydrogenated castor oil recovered from HCO plant under set parameters and is converted to soap by mixing it with 
caustic lye and acidulation vessel is conveyed with the converted HCO soap, in which it is mixed with dilute sulphuric acid which converts the soaps into fatty acids. $8 \%-10 \%$ of glycerine is left out in the acid water which is then drained out and stored for the recovery of glycerine. 12-hydroxy Stearic acid the acidulated product is fed into drier, from the acidulation vessel, wherein, it gets completely dried up through controlled heating. Pre dried 12-HSA further cooled and taken to flaking unit for flaking [3].

Process Description for Castor Oil Polyols Plant: From the storage tank refined castor oil is taken and pumped into premixing vessel. The catalysts is added and mixed properly in the pre mixing vessel and mixed well through an attached auto feeding system. The material is then flow to the preheating vessel through which it is pumped into high pressure reactor. The propylene oxide is taken in to the reactor through pressure reducing valve at a pressure of about $0.6 \mathrm{MPa}$. Refined castor oil is mixed with propylene oxide circulating continuously through cooling heat exchanger with a pump. Effective heat and mass transfer resulted due to continuous circulation to produce qualitative product. After the materials have undergone aging it is then pumped to the reactor vessel. Employing dosing pump the acid is then fed into the acid dosing tank and finally fed into the reaction vessel. The material gets neutralized in the reactor and then pumped to the leaf filters to recover solid materials. Finally a clear liquid is recovered which is stored in a separate storage tank. From the storage tank the crude Polyols is taken and fed into the reaction vessel along with the solvent feed. Before it is sent to the drying unit all the materials are well mixed. Post removal of residual impurities, volatiles and purified Polyols, they are stored in a separate storage tank. Vacuum drying unit produce overhead volatile matters are then condensed and collected in separate storage tanks. The solvent distillation reactor is pumped with the volatile matter from which solvent is recovered and recycled in the process [3].

\section{Castor Oil is Non Toxic}

It is well established from the extensive historical usage of castor oil for human consumption and topical application which is safe. As an investigation studies by the US Department of Health and Human Services (NIH) established as a measure of safety for castor oil usage. In 1990 the feed studies on rats or mice concluded no adverse side effects of castor oil. Dietary concentrations as high as $10 \%$ in 90 days studies, did not affect survival or body weight gains.

\section{Castor Oil, Properties and Characteristics}

Particularly alcohol solubility as castor oil characteristics was reported in 1929. As matter of fact, examination also included of bulk oil in 1919 in addition with the comparison of the characteristics of fresh oil against oil under ten months storage. In the same time the examinations also included refractive index, viscosity, acidity, Halphen number, acetyl value, specific gravity, Wijs iodine value and acetic acid solubility all of which have been listed. It is interesting to note from a historical standpoint, the contrast between current test procedures and those used over 60 years ago.

Castor oil has held relatively high purity, (high for a naturally occurring material). Therefore, it could be subjected efficiently to a number of chemical processes to yield high purity chemical derivatives. The chemical bases for such reactions are the three points of functionality existing in ricinoleic acid: (a) The carboxyl or ester group (b) The single point of un-saturation (c) The hydroxyl group castor oil Chemistry [3].

This functionality may be utilized as follows:

A. At the carboxyl position, through a wide range of esterifications.

B. The hydroxyl group can be acetylated or alkoxyllated.

C. The un-saturation can be altered by hydrogenation or epoxidation.

D. The hydroxyl group can be removed by dehydration to increase the un-saturation of the compound thus yielding drying/polymerizing oil.

E. The hydroxyl position is highly reactive and the molecule can be split at that point by high temperature called pyrolysis and by caustic fusion yielding four useful products of shorter chain length.

Castor oil does have an interesting practical thesis on properties and utilization was presented in a review in 1952. Due to technical changes much of the subject matter is now outdated since then. It is recommended however for the clear, concise and practical description of basic properties and characteristics of castor oil and its derivatives. The chemistry of castor oil with this approach refers to good quality oil and frequently identified as "No.1" castor oil with an expression accepted by the major operators in each producing country. No.1 castor oil being an international standard represents quality that is generally usable for the reactions and applications described in this review. An oil of better quality is required in certain instances $[3,4]$.

\section{Castor Oil's Stability to Oxygen}

Castor oil and many of its derivatives are stabilized by the hydroxyl group, which is beta to the double bond. This hydroxyl group protects the double bond by preventing the formation of hyperperoxides sterically and inductively preventing the formation of peroxides, the intermediate chemical species that form the oxidation of double bonds. Peroxide formation is kinetics based and the method by which oxidative stability of a vegetable oil is measured. Oxidative stability data are derived from an American Oil Chemists method and Active Oxygen Method (AOM). A sample of vegetable oil is heated to $97 \mathrm{oC}$ while air is bubbled through it. AOM number is the number of hours the sample for each vegetable oil took to reach a peroxide value of 70 meqs. Olive oil mentioned to be the nearest stable vegetable oil after castor oil as, like castor oil, it is predominately 
mono-unsaturated but is unlike soy and sunflower oils that are polyunsaturated. Olive oil however lacks a stabilizing factor like castor oil's hydroxyl group. Conclusively castor oil is approximately four times more stable than olive oil $[3,4]$.

\section{Product Applications}

The basic derivatives, Heptaldehyde and Undecylenic acid are used to manufacture various perfumery compounds (Table 1), which in turn are used to manufacture perfumes and synthetic flavors.

Table 1: Castor oil products applications.

\begin{tabular}{|c|c|c|c|}
\hline Sr. No. & $\begin{array}{l}\text { Perfumery } \\
\text { Chemicals }\end{array}$ & $\begin{array}{c}\text { Perfumery } \\
\text { Compounds Prepared }\end{array}$ & $\begin{array}{l}\text { End Use of } \\
\text { Perfumery } \\
\text { Compound }\end{array}$ \\
\hline \multirow[t]{5}{*}{1} & Heptaldehyde & $\begin{array}{l}\alpha \text {-amyl cinnamic } \\
\text { aldehyde }\end{array}$ & $\begin{array}{c}\text { In soap } \\
\text { perfumery }\end{array}$ \\
\hline & & $\begin{array}{l}\text { Nonylenic acid esters } \\
\text { to make 8-n-amyl } \\
\text { butyrolactone }\end{array}$ & $\begin{array}{c}\text { Coconut } \\
\text { Aldehyde } \\
\text { for flavor of } \\
\text { coconut milk }\end{array}$ \\
\hline & & Heptanoic acid & Violet perfume \\
\hline & & $\begin{array}{l}\text { Methyl-n-heptyl ketone } \\
\text { and ester of 3-nonic } \\
\text { acid }\end{array}$ & $\begin{array}{l}\text { Oil of Rue } \\
\text { used in violet } \\
\text { perfume }\end{array}$ \\
\hline & & Heptaldehyde & Jasmine flavor \\
\hline \multirow[t]{5}{*}{2} & $\begin{array}{l}\text { Undecylenic } \\
\text { Acid }\end{array}$ & $\begin{array}{l}\gamma \text {-undecalactone } \\
\text { (Aldehyde C-14) }\end{array}$ & Peach odor \\
\hline & & $\begin{array}{c}\text { Nonylic acid, nonylic } \\
\text { alcohol, nonylic } \\
\text { Aldehyde }\end{array}$ & $\begin{array}{l}\text { Rose and } \\
\text { Orange oil } \\
\text { constitutes }\end{array}$ \\
\hline & & Undecylenic alcohol & $\begin{array}{l}\text { Floral odor } \\
\text { with fatty note }\end{array}$ \\
\hline & & n-decyldehyde & $\begin{array}{l}\text { Spicy Orange } \\
\text { like odor }\end{array}$ \\
\hline & & $\begin{array}{l}\text { Allyl esters of } \\
\text { Undecylenic acid }\end{array}$ & $\begin{array}{l}\text { Odor of } \\
\text { quinches and } \\
\text { as modifier }\end{array}$ \\
\hline
\end{tabular}

\section{Market and Growth Drivers}

Market: India commands the position of is one of the leading manufacturers of Flavors and fragrances in the world. These all bring natural products, used in developing synthetic flavors and fragrances from castor oil derivatives, India is lagging behind. India, being a world leader in Castor seeds and Castor oil production and processing has edge over other countries like Japan, France and Germany who are importing castor oil and manufacturing these perfumery chemicals for further processing into perfumes and Synthetic flavors. Germany, France, Switzerland and Japan are internationally the leading producers of synthetic flavors and fragrances from many natural ingredients, including castor oil derivatives like Undecylenic acid and Heptaldehyde. Definitely there is large international market for perfumery chemicals and estimated market in India is approx. 5000 MT [3,4]. The Global Demand of Flavors and Fragrances is set to increase (Figure 1). The figure below depicts the region wise Demand Break up of Flavors and Fragrance market, estimated for the year 2008.

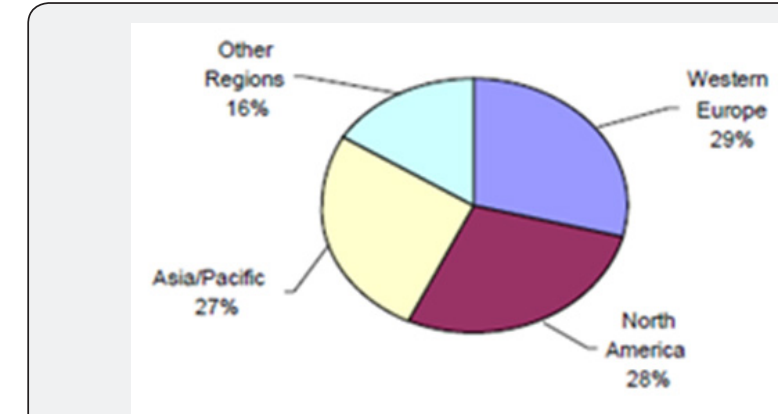

Source: FAO Statics.

Figure 1: Global Demand of Flavor and Fragrances in 2008.

Flavors and fragrance as global demand is estimated to increase at a growth rate of around $4 \%$ per annum. The demand for flavors and fragrances moreover in the Asia/Pacific region is estimated to be growing at a rate of about $7 \%$ per annum through 2008. Growth in the world's most developed markets will continue to be moderate, restrained by market maturity, consolidation in flavors and fragrances using industries and strong downward pressure on prices. Flavor and fragrance is looking for products from natural sources and prefer to use raw materials which are harmless and bio-degradable. In the light of this fact, there is good scope for castor oil derivatives in the global market. Demand for fragrance blends and essential oils will benefit from increased interest in natural and exotic aromas, which are more expensive than their synthetic counterparts $[3,4]$ (Table 2).

Table 2: Statics Data Source: Department of Commerce (GOI).

\begin{tabular}{|c|c|c|c|c|}
\hline $\begin{array}{l}\text { Sr. } \\
\text { No. }\end{array}$ & Products & Years & $\begin{array}{c}\text { Export } \\
\text { Quantity } \\
\text { (MT) }\end{array}$ & $\begin{array}{c}\text { Import } \\
\text { Quantity } \\
\text { (MT) }\end{array}$ \\
\hline \multirow[t]{5}{*}{1} & Heptaldehyde & & & \\
\hline & & 2002-03 & 112 & NA \\
\hline & & 2003-04 & 130.01 & 0.68 \\
\hline & & 2004-05 & 210.57 & 10.44 \\
\hline & & $2005-06$ & 183.74 & NA \\
\hline \multirow[t]{5}{*}{2} & Undecylenic Acid & & & \\
\hline & & 2002-03 & 372.66 & 768.18 \\
\hline & & 2003-04 & 385.02 & 1042.98 \\
\hline & & 2004-05 & 257.96 & 695.72 \\
\hline & & $2005-06$ & 365.91 & NA \\
\hline
\end{tabular}

\section{Technology / Process}

Subjecting castor oil to pyrolysis or destructive distillation at temperature of above $450^{\circ} \mathrm{C}$ under vacuum it under goes decomposition to yield mainly Undecylenic acid and Heptaldehyde, in almost equal quantities (28\% approx). The yields of both acid and Aldehyde, has been found to enhance in the presence of water vapor. The spongy mass post processing, consisted principally of polymerized Undecylenic acid, which can be used in recovering of some quantity of Undecylenic acid. Undecylenic acid esters are used as ingredients for perfumery chemicals. Heptaldehyde is having characteristic Jasmine flavor 
in it and typically it is also known as Jasmine Aldehyde, and it can be converted to Heptanoic acid and Heptanol which are used in manufacture of many perfumery compounds. Castor oil's ingredients' specifications for proposed perfumery chemicals are listed in the Table 3. Figure 2 explains the flow sheet of Heptaldehyde and Undecylenic acid produce $[4,5]$.

Table 3: Specifications for Proposed Perfumery Chemicals.

\begin{tabular}{|c|c|c|c|}
\hline Sr. No. & $\begin{array}{c}\text { Specification } \\
\text { Details }\end{array}$ & Heptaldehyde & Undecylenic Acid \\
\hline 1. & $\begin{array}{c}\text { Appearance } \\
\text { description }\end{array}$ & $\begin{array}{c}\text { Pungent smelling } \\
\text { oily liquid }\end{array}$ & Oily liquid \\
\hline 2. & color & $\begin{array}{c}\text { Colorless to pale } \\
\text { yellow }\end{array}$ & $\begin{array}{c}\text { Water white to } \\
\text { pale yellow }\end{array}$ \\
\hline 3. & $\begin{array}{c}\text { Acid contents } \\
\text { Max } \%\end{array}$ & 5 & $90-95 \%$ minimum \\
\hline 4. & $\begin{array}{c}\text { Aldehyde content } \\
\text { Min \% }\end{array}$ & $90-95$ & $3-5 \%$ maximum \\
\hline 5. & $\begin{array}{c}\text { Refractive index } \\
\text { at } 250 \mathrm{C}\end{array}$ & 1.415 & 1.4880 \\
\hline 6. & Freezing point oC & NA & $21-24$ \\
\hline 7. & Acid value & NA & $295-304$ \\
\hline 8. & Specific gravity & 0.815 & 0.92 \\
\hline 9. & Boiling point oC & $152-154$ & NA \\
\hline
\end{tabular}

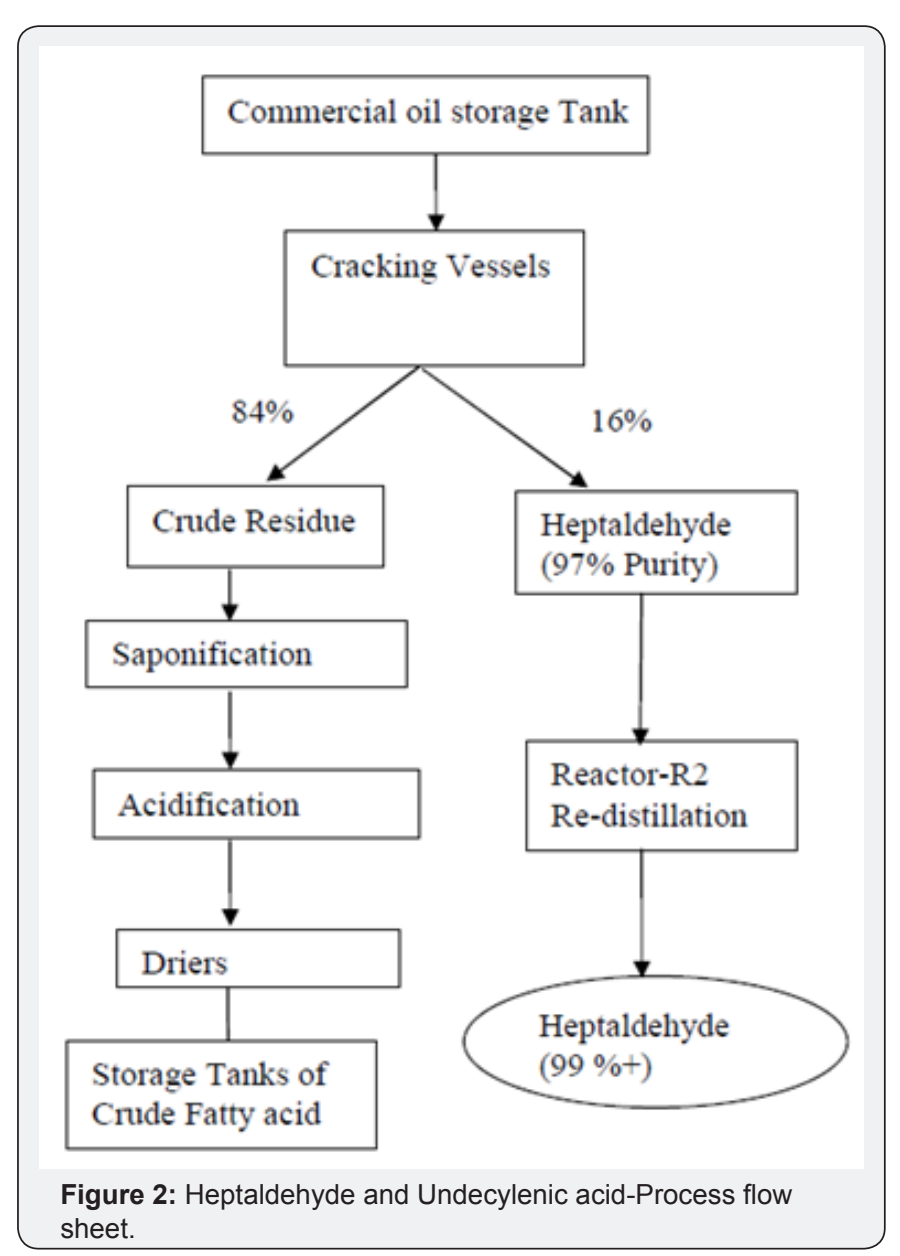

\section{Hydrogenated Castor oil (Flakes/Powder)}

Hydrogen is added to Castor Oil in the presence of a nickel catalyst and the oil, called hydrogenated Castor Oil (Figure 3), which is transformed into a hard, brittle wax with a melt point of approximately 85-86 oC. This wax being extremely insoluble, therefore well suited for products requiring resistance to water, oils, petroleum and petroleum derivatives. HCO makes its availability as flakes or powder which melts to a clear transparent liquid. It is being non-toxic and non-hazardous material. Hydrogenated castor oil is used in manufacturing of greases, it may also be used in paper coating for food packaging as well. The product is made to be available with several different melting points, or in beaded or powdered form. Castor oil that is partially hydrogenated found uses in cosmetic formulations such as lipsticks and stick deodorants. Hydrogenated Castor Oil finds an extensive diversified uses due to its unique combination of physicochemical properties [5].

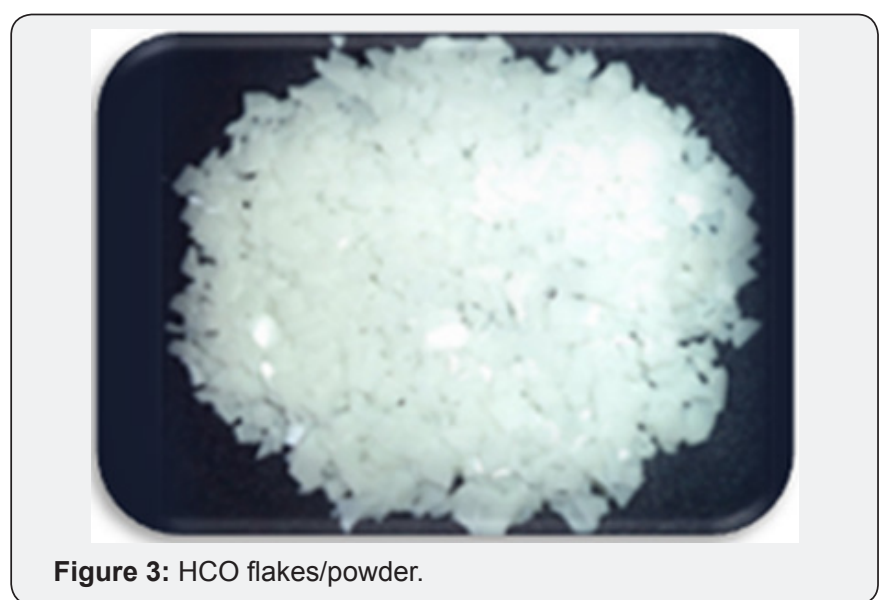

a) In the manufacture of multipurpose Lithium/Calcium grease and high performance aviation grease

b) In the manufacture of soaps \& cosmetics

c) As mould release agent in the processing of plastics and rubbers

d) As a component of specialty wax blends like pencils, crayons, lipsticks and anti-deodorant sticks

e) In the manufacture of hot-melt coatings and sealant requiring resistance to water

f) As a coating agent for paper $\&$ as anti-foaming agent.

g) Automotive refinish Acrylics manufacture

h) Rheological agent that provides thixotropic in paints, coatings, inks, adhesives, sealants and numerous industrial compositions.

i) Thick film chlorinated rubber, epoxy and vinyl coating

j) Flame Retardant and anti-static agent for fiber 
k) Manufacture of Spin finish oil for polyamide fiber

1) In preparation of ointments, emulsified virus vaccines, sustained release capsules, wetting/bodying agent, face paint

m) As plasticizer for cellulosic

n) Processing aid for Color concentrates

o) Surface treatment agents

p) In the manufacture of hot melt adhesives used in packaging books, binding footwear, carpet backing and in product assembly q) Anti-tack and slip additives for processing plastics

r) In the manufacture of specialty chemicals for applications such as metal working, plasticizers and textile auxiliaries in the form of derivatives such as esters, ethylates, sulfates etc (Figure 3) [5-7].

\section{Poly Glycerol Poly Recinoleate (PGPR)}

Polyglycerol Polyricinoleate (PGPR) is a food grade emulsifier consisting of poly-glycerol as the hydrophilic group and interesterified ricinoleic fatty acids as the hydrophobic group (Figure 4). The polyglycerol part of PGPR is mainly found as ditri- or tetra glycerol $(\min 75 \%)$ and $\max 10 \%$ of the polyglycerol part will be found as hepta glycerol or higher.

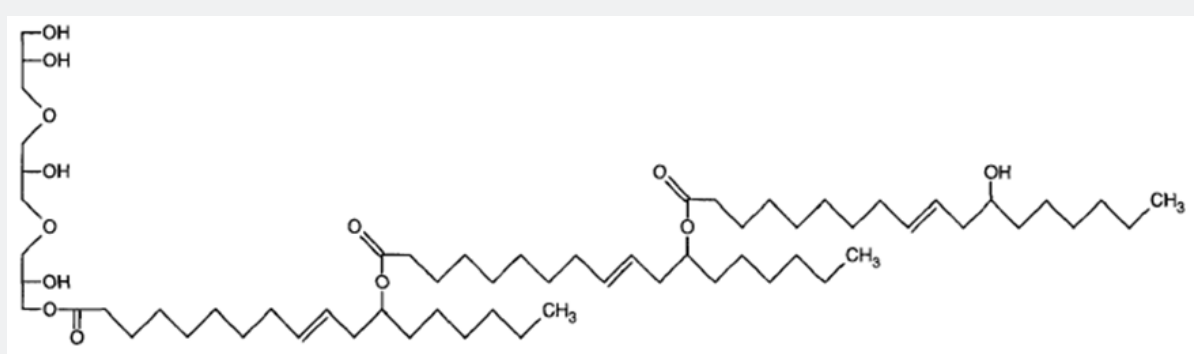

Figure 4: HCO flakes/powder.

Properties: PGPR is a strong water-in-oil emulsifier used to manufacture stable pan release agents for the bakery industry and to stabilize low fat margarine systems with high water content. PGPR contributes in the ability to improve the flow properties in chocolate and vegetable fat coatings by lowering the friction between the particles suspended in the liquid fat phase and so-called "Yield Value" will be reduced and the liquid chocolate mass will flow easily even at a low total fat content [5-7].

\section{Manufacture}

a) Firstly glycerol is heated to temperatures above $200 \mathrm{oC}$ in a reactor. Small percent of alkali is added as catalyst. Condensation of two or more glycerol molecules takes place and water is released and removed over a vacuum pump. Chiefly straight-line polyglycerol units will be created with a smaller amount of cyclic by-products will also be created. In Figure 4 the formation of di- and tri-glycerol is shown, but highly polymerized polyglycerols are also created.

b) Secondly castor oil fatty acids will be heated in a reactor likewise to temperatures above $200 \mathrm{oC}$. The fatty acids from castor oil are found as ricinoleic fatty acids (approx 90\%) and the rest fatty acids are found as oleic-, linoleic- Stearicfatty acids. Fatty acids of the ricinoleic react in a simple linear esterifications process to form inter-esterified ricinoleic fatty acid chains. Water is released during the process and removed over vacuum pump.

c) Thirdly the inter-esterified ricinoleic fatty acids are mixed with the polyglycerol to form a complex mixture of polyglycerol-polyricinoleate molecules of different chain length [8-13] (Figure 5).

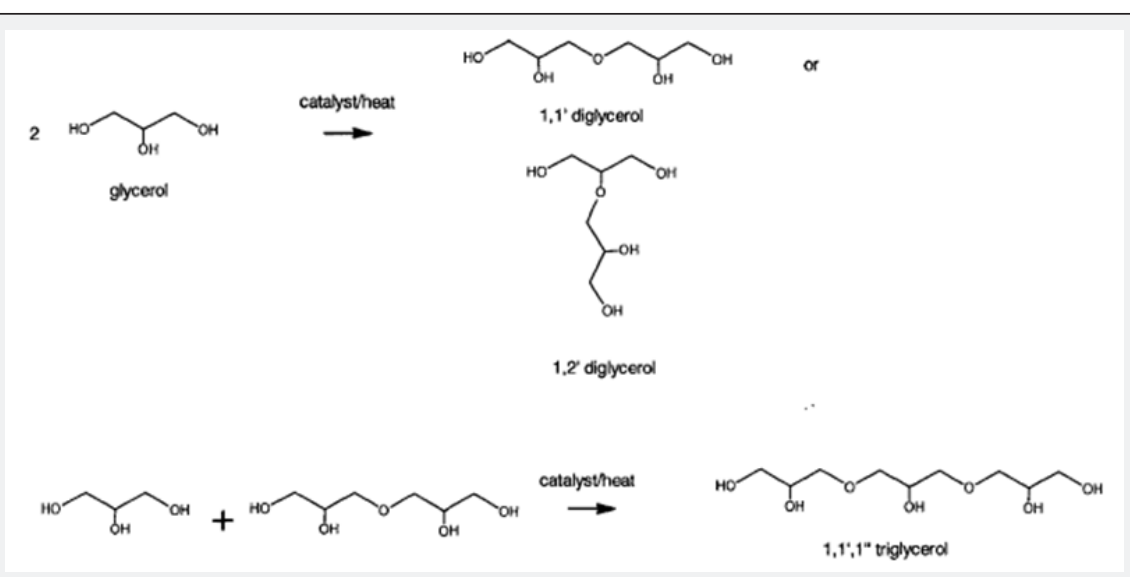

Figure 5: Poly glycerol are made from glycerol by alkaline condensation. 


\section{Application in Foods}

PGPR has a dramatic impact on the flow properties of liquid chocolate and compounds based on vegetable fats. Principally it is understood that PGPR functions by lowering the yield value of the chocolate system, whereas the plastic viscosity hardly is influenced. In consideration of the practical implication that PGPR always is added as a co-emulsifier in combination with lecithin or ammonium phosphatide and helps as emulsifiers mainly reduce the plastic viscosity [13-15]. Cocoa butter and specialty vegetable fats are quite expensive raw materials, so the manufactures of chocolate and compounds can benefit from the effect of PGPR and lower the total fat content in the ready to consume products. Also from a health point of view fat reduction in chocolate and compounds are improving the quality in the eyes of the consumers. Due to the strong effect on the yield value in chocolate it is possible to make the chocolate flow during production by use of much less fat. Therefore PGPR is an important tool in manufacturing of various types of chocolatetype products. The effect of PGPR as an ingredient of chocolate is further described by Steven T. Beckett, Schantz, B. and Rohm, H.

Published toxicological studies, with scientific evaluation enables the GRAS determination on polyglycerol poly ricinoleate combined with an evaluation of the consumption pattern of vegetable fat coatings in the US.JECFA has established an accepted daily intake (AD1 value) for polyglycerol poly ricinoleate to 0-7.5 $\mathrm{mg} / \mathrm{kg}$ body weight per day. The statistical data on consumption of vegetable fat coatings by the US population compared with the established AD1 value on polyglycerol poly ricinoleate clearly support the safety of the use of polyglycerol polyricinoleate at a maximum rate of $0.3 \%$ in vegetable fat coatings [14-19].

\section{Undecylenic Acid}

The pyrolysis of castor oil at $700 \mathrm{oC}$ under reduced pressure has been used to yield Heptaldehyde and Undecylenic acid. (It is the chemical decomposition of organic materials by heating in the absence of oxygen or any other reagents, beside steam). For producing alcohol from Heptaldehyde it can be further hydrogenate for use in the plasticizers. Hydrolysis is another method via the use of Methyl Undecylenate. Methyl Undecylenate is hydrolyzed to give Undecylenic Acid [20-25].

$\left(\mathrm{CH}_{2}=\mathrm{CH}\left(\mathrm{CH}_{2}\right)_{8} \mathrm{COOCH}_{3}\right)$ Methyl Undecylenate $\rightarrow \mathrm{H}_{2} \mathrm{O} \rightarrow$ Undecylenic Acid $\left(\mathrm{CH}_{2}=\mathrm{CH}\left(\mathrm{CH}_{2}\right)_{8} \mathrm{COOH}\right)$

Applications: Undecylenic acid has a long history as antifungal drug. Many types of fungal infections can be treated with its application. Undecylenic acid can be used as a surfactant in hair lotions and as biocide in soaps and deodorants. It goes as a starting material for Nylon 11 [25-27].

\section{Sebacic Acid}

Sebacic acid, a 10-carbon di carboxylic acid, can be synthesized from phenols and cresols, but castor oil oxidation is considered a greener $\|$ process. Manufacture of sebacic acid is done heating castor oil to high temperatures (about 250oC) with the use of alkali. Result of this treatment saponifies the castor oil to ricinoleic acid which is then cleaved to give capryl alcohol (2-octanol) and sebacic acid [20-23].

Applications: One of the many uses of sebacic acid is in the manufacture of Nylon 6-10. Sebacic acid and their derivatives like Azelaic acid finds variety of industrial uses in plasticizers, lubricants, hydraulic fluids, cosmetics, candles, etc. They are used in the synthesis of polyamide and alkyd resins. An isomer, isosebacic acid, has other applications in the manufacture of extrusion plastics, adhesives, polyesters, polyurethane resins and synthetic rubber. Sebacic acid is also used as an intermediate for aromatics, antiseptics and painting materials. Thousands of potential starting materials can be obtained from esters. It is used as a corrosion inhibitor in metalworking fluids and as a complexion agent in greases. Sebacic acid when mixed with amines yields a very effective water soluble works as corrosion inhibitor for metal working fluids. Lithium hydroxyl stearate complex greases often utilize dibasic acids such as sebacic acid for the more unusual performance parameters. These greases are prepared from the esters of sebacic acid, and are being developed for specific performance criteria under varying conditions. Sebacic acid esters are used as plasticizers also for vinyl resins and in the manufacture of dioctyl sebacate; a jet lubricant and lubricant in air cooled combustion motors [24-30] (Table 4).

Table 4: Current demand supply estimates for the select grades of castor oil (Santhanam et al. [6]).

\begin{tabular}{|c|c|c|c|}
\hline Product & Demand & $\begin{array}{c}\text { Current } \\
\text { Demand } \\
\text { Supply Gap }\end{array}$ & $\begin{array}{c}\text { Future } \\
\text { Demand }\end{array}$ \\
\hline $\begin{array}{c}\text { Hydrogenated } \\
\text { Castor Oil } \\
\text { (HCO) }\end{array}$ & Medium & Medium & Very high \\
\hline $\begin{array}{c}\text { 12-Hydroxy } \\
\text { Stearic Acid } \\
\text { (12 HAS) }\end{array}$ & Medium & Medium & very high \\
\hline $\begin{array}{c}\text { Sulfated/ } \\
\text { Sulfonated } \\
\text { Castor oil } \\
\text { Turkey red }\end{array}$ & Medium & Medium & Medium-High \\
\hline $\begin{array}{c}\text { Dehydrated } \\
\text { Castor oil DCO }\end{array}$ & Medium-High & Medium & Very high \\
\hline $\begin{array}{c}\text { Undecylenic } \\
\text { acid }\end{array}$ & Very High ${ }^{1}$ & Very High ${ }^{1}$ & Very High \\
\hline Ricinoleic acid & Medium & Medium & Low-Medium \\
\hline \begin{tabular}{c} 
Sebacic acid \\
\hline
\end{tabular} & Very High2 & Medium-High & Low \\
\hline
\end{tabular}

\section{Notations for Demand}

a) ${ }^{1,2}$ Very High: 50,000 $\mathrm{T}$ and above per ear

b) High: 30,000 - 50,000 $\mathrm{T}$ per year

c) Medium-High: 15,000-30,000 T per year

d) Medium: 5,000-15,000 $\mathrm{T}$ per year

e) Low-Medium: 1,000-5,000 $\mathrm{T}$ per year

f) Low: Less than 1,000 $\mathrm{T}$ per year 


\section{Notations for Demand-Supply Gap}

a) Medium: There exists some demand over and above supply, but there has not been a significant amount of demand that has gone unmet

b) Medium-High: There have been some instances where a significant demand has gone unmet

c) High: There have been many instances where a significant demand in the market has gone unmet

d) Low: There have been very few instances when a significant demand has gone unmet

e) NA: denotes that information on demand supply gap is not available owing to the negligible demand volume

\section{Transesterification of Castor Oil}

Deshpande DP have studied the Transesterification of castor oil in a batch reactor employing $\mathrm{KOH}$ as a catalyst. They have chosen the variables such as residence time, oil to methanol ratio, catalyst concentration and reaction time. Mohammed H. et al. in their studies of transesterification of castor oil with methanolic $\mathrm{KOH}$, the authors varied operating conditions; $\mathrm{KOH}$ catalyst concentration 2.1-3g for $250 \mathrm{ml}$ feedstock; temperature 30 70oC; reaction time 30-360 minutes. The authors have reported ester (biodiesel) content $48 \%$ which is highest and glycerine $52 \%$. They carried the reaction with $65 \mathrm{ml}$ methanol and 2.4 g KOH catalyst, reaction time of 360 minutes at a temperature of $70 \mathrm{oC}$ and converting $250 \mathrm{ml}$ castor oil feedstock. They also exercised parallel experiments involving two stage process viz esterification by acid followed by normal transesterification. Recommendation of this procedure was proposed by Marchetti. Esterifications process comprised of two stages by Mohammed et al reported the ester content up to $85 \%$. The authors confirmed castor biodiesel viscosity of $13.75 \mathrm{~mm}^{2} \mathrm{sec}^{-1}$ and density 0.9279 at $150 \mathrm{C}$. The castor oil used by the authors having viscosity of $239.39 \mathrm{~mm}^{2} \mathrm{sec}^{-1}[30-34]$.

The fatty acids consist of approximately $80-90 \%$ ricinoleic acid, 3-6\% linoleic acid, 2-4\% oleic acid and 1-5\% saturated fatty acids. The high content of ricinoleic acid is the reason for the versatile value of castor oil in technology (Table 5). In Comparison with other vegetable oils, castor oil has a very high proportion of simply unsaturated fatty acids (18:1). A high proportion of those acids can be comparatively found only in the oil of the high oleic (HO) sunflower, appearing, however, as oleic acid. In castor oil it is ricinoleic acid, the only unsaturated fatty acid occurring in natural vegetable oils with a hydroxyl function of the carbon atom 12 . The extraordinarily high viscosity of castor oil is attributed to the presence of the hydroxyl group. The variation of specific gravity with residence time in their study appeared in a similar trend as that of viscosity. Decrease in the Specific gravity was observed from 0.9096 to 0.882 as residence time is increased from 30 to 45 minutes, further increase in residence time from 60 to 90 minutes the specific gravity increased 0.882 to 0.9026 while acid value of biodiesel product decreased with increasing reaction time and saponification value decreased with increasing reaction time and further increases [34-36].

Table 5: Composition of castor oil (Deshpande et al. [7]).

\begin{tabular}{|c|c|}
\hline Acid name & Average Percentage Range \\
\hline Ricinoleic acid & $85-95 \%$ \\
\hline Oleic acid & $6-2 \%$ \\
\hline Linoleic acid & $5-1 \%$ \\
\hline Linolenic acid & $1-0.5 \%$ \\
\hline Stearic acid & $1-0.5 \%$ \\
\hline Dihydroxystearic acid & $0.5-0.3 \%$ \\
\hline Others & $0.5-0.2 \%$ \\
\hline
\end{tabular}

Table 6 presents their data of variation in viscosity with time. The authors observed increase in specific gravity with increasing temperature, the same changes were observed in acid value. They also observed that at lower temperature of $30 \mathrm{oC}$ the biodiesel product gave lower viscosity and they further increased the temperature up to $50 \mathrm{oC}$. Acid value had shown similar trend as that of viscosity. Sap value too shown similar trend as that of specific gravity (Table 7) [35-37].

Table 6: Variation of viscosity Verses time (Deshpande et al. [7]).

\begin{tabular}{|c|c|c|c|c|}
\hline $\begin{array}{c}\text { Time of } \\
\text { Run (min) }\end{array}$ & $\mathbf{3 0}$ & $\mathbf{4 5}$ & $\mathbf{6 0}$ & $\mathbf{9 0}$ \\
\hline $\begin{array}{c}\text { Kinematic } \\
\text { viscosity } \\
\text { (cSt) }\end{array}$ & 18.12 & 14.10 & 14.51 & 15.15 \\
\hline $\begin{array}{c}\text { Specific } \\
\text { gravity }\end{array}$ & 0.9096 & 0.890 & 0.90 & 0.9026 \\
\hline Acid value & 1.26 & 0.57 & 0.64 & 0.68 \\
\hline Sap value & 177.6 & 173.4 & 174.3 & 174.9 \\
\hline
\end{tabular}

Table 7: Viscosity variation with oil to alcohol ratio (Deshpande et al. [7]).

\begin{tabular}{|c|c|c|c|c|}
\hline $\begin{array}{c}\text { Oil to } \\
\text { Alcohol } \\
\text { Mole Ratio }\end{array}$ & $\mathbf{1 : 6}$ & $\mathbf{1 : 9}$ & $\mathbf{1 : 1 0}$ & $\mathbf{1 : 1 2}$ \\
\hline $\begin{array}{c}\text { Kinematic } \\
\text { viscosity } \\
\text { (cSt) }\end{array}$ & 18.18 & 14.10 & 19.84 & Nil \\
\hline $\begin{array}{c}\text { Specific } \\
\text { gravity }\end{array}$ & 0.9036 & 0.8820 & 0.9112 & Nil \\
\hline Acid value & 0.97 & 0.57 & 0.84 & Nil \\
\hline Sap value & 173.4 & 176.1 & 176.8 & Nil \\
\hline
\end{tabular}

According to their observation the specific gravity of the product was lowest at $1 \mathrm{wt} \%$ catalyst concentration and increased with increasing catalyst concentration up to $2 \mathrm{wt} \%$. The specific gravity of product was increased at lowest concentration at $0.5 \mathrm{wt} \%$. Specific gravity was higher due to probably of lower catalyst concentration of $0.5 \mathrm{wt} \%$ conversions were very low. Therefore with referring to above data, $1 \mathrm{wt} \%$ catalyst concentration may be optimum in the range of operating condition studied. The viscosity decreased with initially up to $1 \mathrm{wt}$ \% catalyst concentration and then increased up to $2 \mathrm{wt} \%$ of 
catalyst concentration. Initially specific gravity decreased up to $1 \mathrm{wt}$. \% of catalyst concentration and further found to increased and acid value shown similar trend as that of viscosity. Sap value was found practically constant post $1 \mathrm{wt} \%$ catalyst concentration. The authors have supported their data with the plot of figures as presented by Figures 6-11 [35,36].

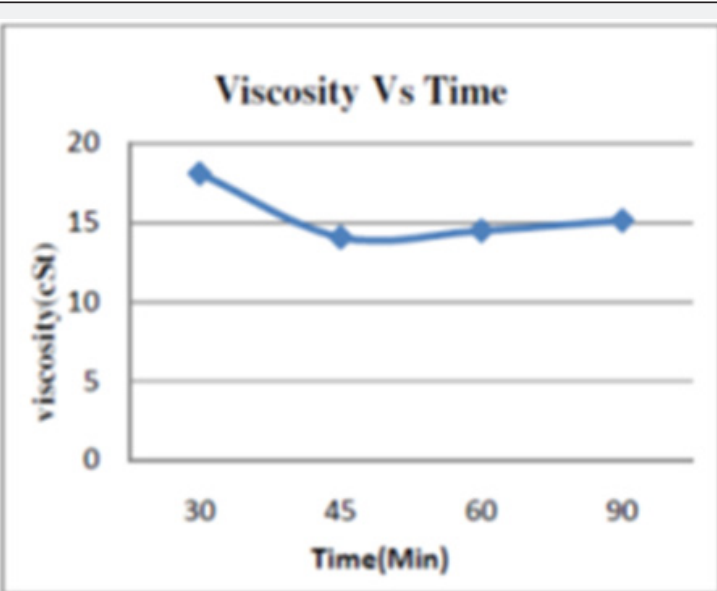

Figure 6: viscosity variation vs. time (Deshpande et al. [7]).

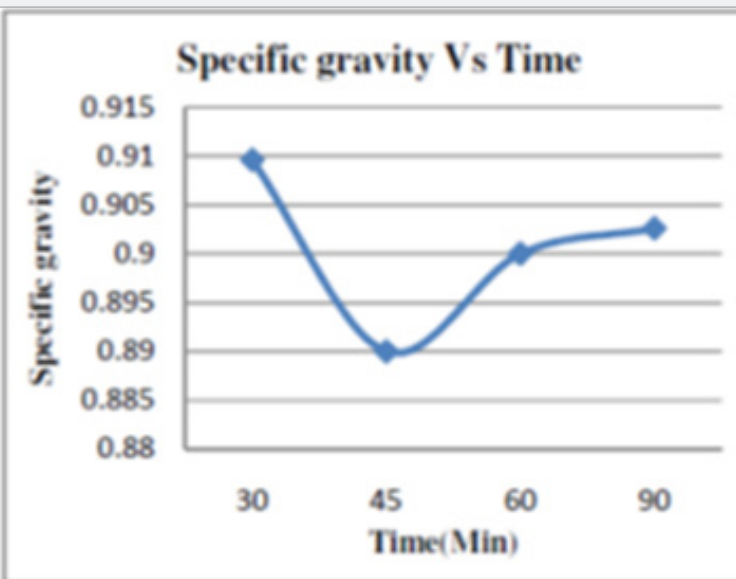

Figure 7: specific gravity vs. reaction time (Deshpande et al. [7]).

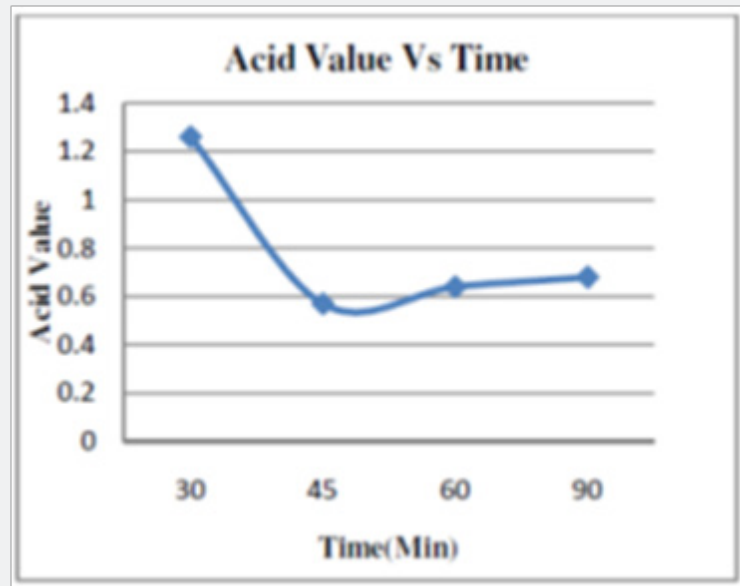

Figure 8: Acid value vs. reaction time (Deshpande et al. [7]).

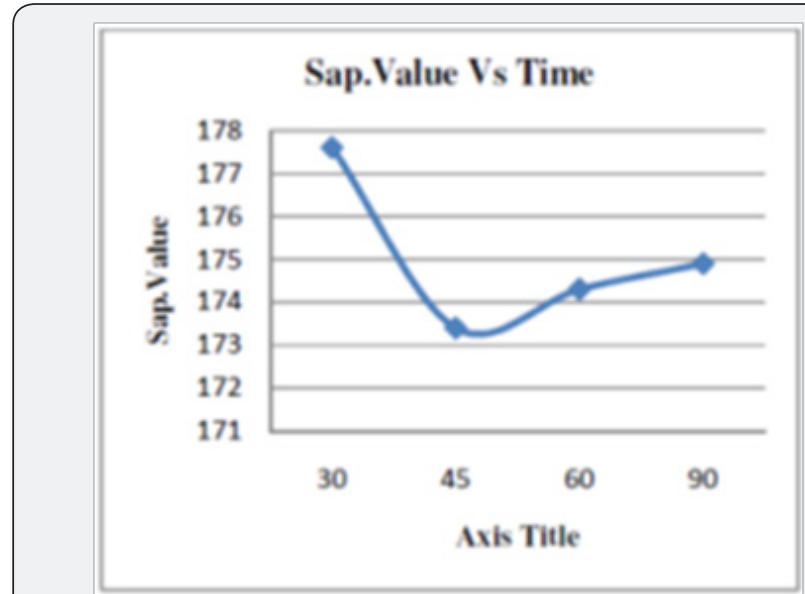

Figure 9: Sap value vs. reaction time (Deshpande et al. [7])

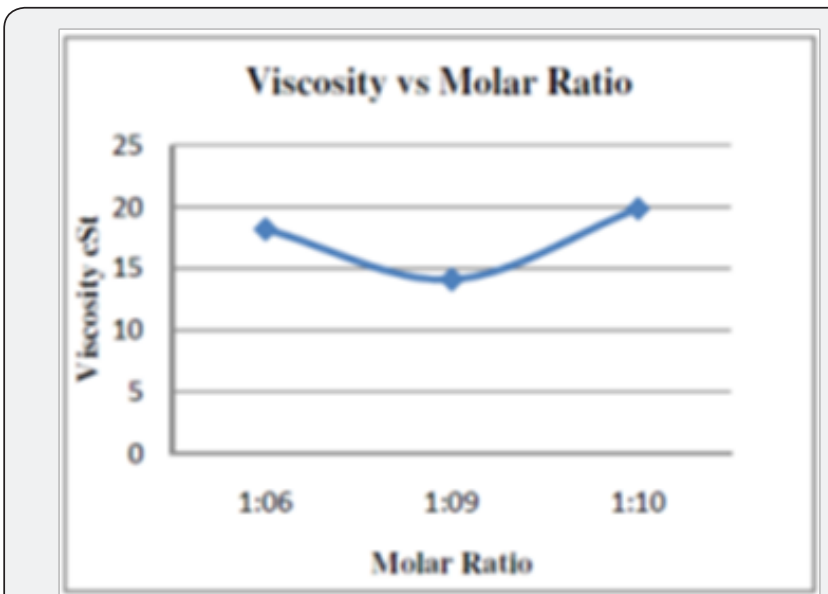

Figure 10: Viscosity variations vs. molar ratio (Deshpande et al. [7]).

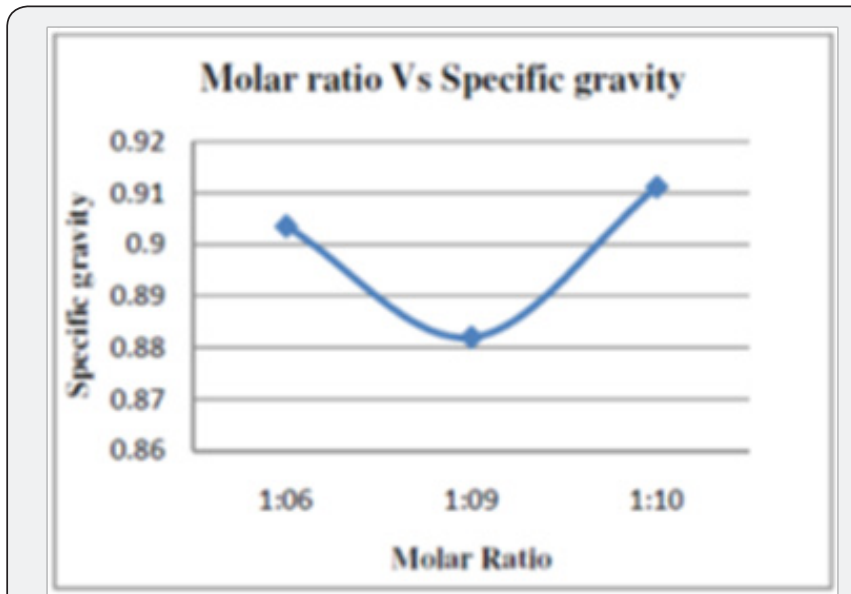

Figure 11: molar ration vs. specific gravity (Deshpande et al. [7]).

\section{Conclusion}

Global demand is estimated to increase at a growth rate of around $4 \%$ of flavors and fragrance from castor oil per annum. Much above the demand for flavors and fragrances in the Asia/ 
Pacific region is estimated to be growing at a rate of about $7 \%$ per annum through 2008. Growth in the world's most developed markets will continue to be moderate, restrained by market maturity, consolidation in flavors and fragrances using industries and strong downward pressure on prices. Flavor and fragrance is looking for products from natural sources and prefer to use raw materials which are harmless and bio-degradable. In the light of this fact, there is good scope for castor oil derivatives in the global market. Fragrance blends and essential oils' demand will benefit from increased interest in natural and exotic aromas, which are known to be more expensive than their synthetic counterparts.

\section{References}

1. Castor Oil Chemistry its Derivatives and Their Applications: Technical Bulletin. International Castor Oil Association (ICOA).

2. Mott Mac Donald Castor Oil Derivatives Perfumery Raw Materials p. 1-7.

3. Modak SN, Kane JG (1965) Studies in estolides I Kinetics of estolide formation and decomposition. J Am Oil Chem Soc 42: 428-432.

4. Beckett ST (2005) The Science of Chocolate. (Royal Society of Chemistry, 2000. p 81 ff) Lebensm Wiss u Technol 3(8): 41-45.

5. Schantz B, Rohm H (2005) The Science of Chocolate. (Royal Society of Chemistry 2000 p 81 ff) Lebensm Wiss u Technol 3(8): 41-45.

6. N Santhanam, M Balu, S Sreevatsan comprehensive castor oil report. The definitive guide for entrepreneurs and investors.

7. Deshpande DP, HaralSS, Gandhi SS, GanvirVN (2012) Transesterification of Castor oil. ISCA J Engineering Sci 1(1): 2-7.

8. Frank D, Gunstone, John L, Harwood Albert, J Dijkstra (2007) The Lipid Handbook. CRC Press, USA, pp. 1472.

9. James AT, Hadaway HC, Webb JP (1965) The biosynthesis of ricinoleic acid. Biochem J 95(2): 448-452.

10. Zinc ricinoleate. Environmental Working Group.

11. Rider TH (1931) The purification of sodium ricinoleate. Journal of the American Chemical Society 53: 4130-4133.

12. Vieira C, Evangelista S, Cirillo R, Lippi A, Maggi CA, et al. (2000) Effect of ricinoleic acid in acute and sub chronic experimental models of inflammation. Mediators Inflamm 9(5): 223-228.

13. (2008) L Oreal cosmetic composition comprising a continuous oily phase.

14. Thomas, Alfred (2005) Fats and Fatty Oils. Ullmann's Encyclopedia of Industrial Chemistry. Weinheim: Wiley VCH.

15. Cassel man, William Gordon (2014) Castor. Bill Cassel man's Canadian Word of the Day.
16. (2013) Aldrich Handbook of Fine Chemicals and Laboratory Equipment. Sigma Aldrich.

17. Mutlu H, Meier MAR (2010) Castor oil as a renewable resource for the chemical industry. European Journal of Lipid Science and Technology 112(1): 10-30.

18. Mc Guire, Nancy (2004) Taming the Bean. The American Chemical Society.

19. Brady George S, Clauser, Henry R, Vaccari John (1997) Materials Handbook (14 ${ }^{\text {th }}$ Edn.); New York: McGraw Hill, USA.

20. Older, Jules (2000) Back road and off road Biking. Mechanicsburg PA Stack pole Books. p. 37 .

21. Marter AD (1981) Castor: Markets, Utilization and Prospects. Tropical Product Institute, G152, p. 55-78.

22. Weise EA (1983) Oil seed crops. Tropical Agriculture Series p. 31-53.

23. Salunke DK, Desai BB (1941) Post harvest Biotechnology of Oil Seeds. CRC Press, USA, pp. 161-170.

24. Dole KK, Keskar VR (1950) Dehydration of castor oil. Curr Sci 19(8): 242-243.

25. Nkpa NN, Arowolo TA, Akpan HJ (1989) Quality of Nigerian palm oil after bleaching with local treated clays. Journal of the American Oil Chemists Society 66(2): 218-222.

26. Carr RA (1976) Refining and degumming system for edible fats and oils. JAOCS 55: 766-770.

27. Janson H Castor oil production and processing. United Nations p. 4-13.

28. Lew Kowitseh JI (1909) Chemical Technology and Analysis of oils.

29. JC Chevalier Hoehn (1914) Process of hydrogenating unsaturated fatty material.

30. Proctor, Gamble (1918) Hydrogenation of fats and oil.

31. Dierig, David A (1995) Lesquerella. New Crop Factsheet. Center for New Crops \& Plant Products. Purdue University, USA.

32. Dierig, David A (2002) Lesquerella. The National Non-Food Crops Centre.

33. Wood M (2001) High Tech Castor Plants May Open Door to Domestic Production. Agricultural Research Magazine 49(1).

34. Wilson R, Van Schie BJ, Howes D (1998) Overview of the preparation, use and biological studies on polyglycerol polyricinoleate (PGPR). Food Chem Toxicol 36(9-10): 711-718.

35. BASF Technical data sheet on Cremophor EL.

36. Busso C, Castro Prado MA (2004) Cremophor EL stimulates mitotic recombination in uvsH//uvsH diploid strain of Aspergillus nidulans. An Acad Bras Cienc 76(1): 49-55. 
(C) This work is licensed under Creative CC Commons Attribution 4.0 License

BY DOI: 10.19080/OMCIJ.2018.06.555692

\begin{tabular}{|l|}
\hline \multicolumn{1}{|c|}{ Your next submission with Juniper Publishers } \\
will reach you the below assets \\
- Quality Editorial service \\
- Swift Peer Review \\
- Reprints availability \\
- E-prints Service \\
- Manuscript Podcast for convenient understanding \\
- Global attainment for your research \\
- Manuscript accessibility in different formats \\
( Pdf, E-pub, Full Text, Audio) \\
- Unceasing customer service \\
Track the below URL for one-step submission \\
https://juniperpublishers.com/online-submission.php \\
\hline
\end{tabular}

